\title{
La lectura como estrategia de inclusión social en las ferias del libro del Estado de México
}

\author{
Carmina Vivero Domínguez*
}

Artículo recibido:

31 de agosto de 2021

Artículo aceptado:

6 de diciembre de 2021

Artículo de investigación

\section{RESUMEN}

La investigación tiene como objetivo el análisis de la lectura como estrategia de inclusión social en las ferias del libro del Estado de México, para contar con un panorama que visibilice las realidades en relación al tema. Se realizó a partir de un enfoque cualitativo, el cual permitió analizar, dentro de las ferias del libro, las siguientes tres categorías: espacio físico, comercialización y actividades, a fin de poseer una visión interpretativa hacia el objeto de estudio.

Como parte de los resultados se puede afirmar que la lectura como estrategia de inclusión social en las ferias del libro del Estado de México comienza gradualmente a vislumbrarse en ciertas acciones que se observaron a

* El Colegio Mexiquense A. C., México

carmiluna10@hotmail.com

INVESTIGACIÓN BIBLIOTECOLÓGICA, vol. 36, núm. 90, enero/marzo, 2022, México, ISSN: 2448-8321 pp. 165-177 
partir de las tres categorías antes mencionadas; sin embargo, esta manifestación parece ser de manera transitoria. Fundamentalmente es la parte comercial a la que se atribuye mayor ponderación y esto se puede ver desde la planeación que las respalda, ya que cada feria se organiza de acuerdo con un manual de expositores en donde prevalece la parte productiva y económica, dejando de lado a la feria como un espacio cultural que sirve para lograr, entre otras cosas, que la lectura propicie inclusión social.

Palabras claves: Lectura; Inclusión Social; Ferias del Libro; Estado de México

Reading as a strategy for social inclusion in book fairs in the State of Mexico

Carmina Vivero Dominguez

\section{Abstract}

The research aims to analyze reading as a strategy for social inclusion in book fairs in the State of Mexico to have a panorama that makes visible the realities in relation to the subject.

It was carried out from a qualitative approach, which allowed to analyze, within the book fairs, the following three categories: physical space, commercialization and activities, in order to have an interpretive vision towards the object of study.

As part of the results, it can be affirmed that reading as a social inclusion strategy in the book fairs of the State of Mexico gradually begins to be glimpsed in certain actions that were observed from the three aforementioned categories, however this manifestation seems to be temporarily.

It is fundamentally the commercial part to which the greatest weight is attributed and this can be seen from the planning that supports them since each fair is organized according to an exhibitors manual where the productive and economic part prevails, leaving aside the fair as a cultural space that serves to achieve, among other things, that reading fosters social inclusion.

Keywords: Promotion of Reading; Social Inclusion; Books Fairs; State of Mexico 


\section{INTRODUCCIÓN}

Considerar la lectura como un asunto de interés público es una preocu$\checkmark$ pación reciente, ya que históricamente esta práctica cultural ha sido un privilegio reservado sólo para unos cuantos, quienes ejercían el monopolio del conocimiento, la ley o la religión. Para Deberti Martins (2011: 109) "La cultura escrita ha sido por largo tiempo privilegio de la clase dominante". Lejos de haber servido como medio de formación y liberación, la lectura fue, por mucho, instrumento de poder y dominación. Gradualmente, a partir de los nuevos paradigmas en que se mueve la sociedad contemporánea, a la lectura se le han sumado diversas funciones de comunicación, participación, desarrollo personal y colectivo. "Las distintas etapas de la historia de la humanidad han otorgado un lugar de privilegio a la lectura y a la escritura. Cada una de ellas ha marcado momentos particulares en la evolución del tema y ha incidido de forma diferente en su desarrollo" (Ceretta Soria, 2012: 36). De ahí que, actualmente, se recurre a ella para cumplir una función integradora como herramienta en la construcción de la ciudadanía y el cambio cultural hacia una sociedad incluyente y libre de discriminación.

Así, poco a poco, el tema de la lectura ha tomado auge desde las campañas de inclusión social para formar parte en las estrategias y hacer frente a los altos índices de discriminación y desigualdad.

Ante esta búsqueda de soluciones y oportunidades en la inclusión se intentan obtener condiciones favorables para que todas las personas alcancen un nivel de bienestar que les permita ejercer sus derechos y acceder a la justicia cultural en aras de vivir plenamente con igualdad de circunstancias. Así lo piensa también De Souza Siqueira (2016: 93), cuando menciona que "la lectura es un factor clave para la vida en sociedad; sin embargo, hay personas que no se han apropiado de esta práctica”. Y es que históricamente esto ha sido un ideal que, desafortunadamente y en muchos casos, está lejos de conseguirse debido a que el dominio de intereses económicos, políticos, sociales o religiosos ha dejado huellas de pobreza, discriminación, poca o nula educación, así como una larga lista de factores limitantes en el acceso a la cultura y particularmente a la lectura. Pero, a pesar de muchas circunstancias en contra, se busca alcanzar la equidad. Ante esto, cabe preguntarse: ¿puede la lectura servir como estrategia de inclusión social? Y si es así, ¿podría ser desde una feria del libro?

Una vez descrito este panorama, es necesario puntualizar que la presente investigación se enfoca en la lectura como estrategia de inclusión social en las ferias del libro, específicamente las del Estado de México. Para ello es necesario hacer hincapié y comprender que la génesis de éstas es la venta de material 
de lectura, razón justificada por la que han sido escasamente exploradas desde otros ámbitos que no sean económicos.

Ya lo mencionan Pérez Camacho y López Ojeda (2015: 50):

Si bien algunas ferias le dan seguimiento a sus eventos, no van más allá de los impactos cuantitativos que se consignan y sirven básicamente como autopromoción, evaluación (sobre todo en ventas), y planeación de los próximos eventos. Entre la información que generalmente se recaba se encuentran: números de asistentes, editoriales participantes, venta y presentación de libros, diálogos con autores, actividades culturales complementarias, etcétera. No cabe duda que es importante recabar este tipo de informaciones pero tal vez hace falta saber cómo las ferias del libro contribuyen a otras prácticas, acercamientos y significados del acto de leer.

Por supuesto que se entiende el papel del marketing en las ferias del libro, finalmente cada metro cuadrado debe ser vendido y los expositores tienen que salir satisfechos con el resultado, garantizando así su participación en la próxima edición. Sin embargo, también es importante que los organizadores de las ferias construyan un discurso con una postura cooperativa, un concepto amplio de feria, asumida como un espacio cultural y educacional intrínsecamente relacionado con la mejora de la ciudadanía.

Por eso, en cuanto a la lectura para el público en general y los grupos vulnerables en particular, así como para los fines de la presente investigación, se planteó la siguiente interrogante: ¿qué estrategias de inclusión social han seguido las ferias del libro del Estado de México? Porque definitivamente hoy en día estas ferias tienen que ser más que un mercado de letras. Al respecto, López Villalobos (2014: 114) muestra un panorama de lo que ocurre con las ferias cuando menciona que "En la mayoría de estos eventos, los grandes grupos editoriales suelen acaparar los espacios disponibles y, en estos casos, la facturación -valga decir el factor económico- suele ser el indicador más importante para determinar el éxito de la feria".

De ahí que las ferias del libro deben planearse y ejecutarse, además de sus ventas, en relación a objetivos claros destinados a la promoción lectora que vayan firmemente encaminados a la inclusión social y permeen no sólo in situ de la feria, sino en el entorno cotidiano del asistente, ya que estos espacios culturales asumen un papel cada vez más importante en la democratización del acceso a la lectura, por ser un stand o vitrina que posibilita encuentros entre lectores y lecturas.

Las ferias deben empezar a visualizarse más allá de espacios complejos económicos, también deben pensarse como espacios de integración cultural. Al respecto, Ramírez Alvarado $(2015,2016)$ analiza detalladamente la necesidad de incentivar todas y cada una de las funciones de la feria, ya que definitivamente pueden explorarse aún más. 


\section{Metodología}

El escenario geográfico que delimitó el trabajo de investigación fue el Estado de México. Para identificar las ferias del libro objeto de estudio se utilizó la plataforma del Sistema de Información Cultural del Estado, en la cual se encuentran registradas las seis siguientes: Feria Internacional de Libro Estado de México (FILEM), Feria Internacional del Libro de Nezahualcóyotl, Feria Internacional del Libro de Texcoco, Feria del Libro de Chapingo, Feria del Libro del Tecnológico de Estudios Superiores de Ecatepec, y Feria del Libro y la Lectura de Tlalnepantla.

Esta investigación se realizó entre los meses de septiembre 2020 y agosto 2021, periodo que coincidió con la pandemia por COVID-19, lo que irremediablemente le dio un giro al análisis propuesto. Se tenía contemplado realizar trabajo de campo pero las ferias cambiaron a la modalidad virtual o incluso algunas se suspendieron, ante eso se optó por rescatar la manera en que estas ferias de libro se han venido desarrollando.

La investigación tuvo un enfoque cualitativo, el cual permitió, a través de este método interpretativo, entender la causa-efecto en lo que respecta al comportamiento de las ferias para la lectura como estrategia de inclusión social.

Se realizó trabajo de gabinete a partir del análisis de fuentes como los manuales para expositores que proyectan las ferias de libro, las páginas oficiales, sus redes sociales que permitieron ver fotografías y videos con recorridos virtuales, y la prensa que siguió de cerca los eventos desde donde se identificaron palabras inaugurales y de clausura, mismas que permitieron acercarse al objeto de estudio. Las ferias tienen la característica de ser ampliamente difundidas a través de los medios de comunicación; para el caso del Estado de México esto no fue la excepción, por lo que hubo material suficiente de consulta que permitió desarrollar el trabajo de gabinete.

Para abordar a las ferias del libro se tomó como referencia el enfoque de Pastor Homs (2004), por lo que se hizo una clasificación de posibles tipos de barreras que impiden la inclusión social en las ferias de libro:

- Barreras físicas: son aquellas que impiden el acceso físico al espacio o a determinadas partes del mismo.

- Barreras económicas: son las que impiden a los visitantes con bajos ingresos acudir a ese espacio cultural.

- Barreras intelectuales: son aquellas que impiden a las personas sin un alto nivel formativo o con problemas de aprendizaje una mínima comprensión del significado de lo que se encuentra expuesto en ese espacio. 
- Barreras informativas: son aquellas que impiden a las personas el conocimiento de la oferta educativa de lo que se expone en ese espacio cultural.

Derivado de las barreras se propusieron tres categorías de análisis a observarse en las ferias del libro del Estado de México, mismas que permitieron conocer la capacidad que tienen éstas para brindar, desde la lectura, apertura a la inclusión social. Las categorías son espacio físico, comercialización, y actividades.

\section{Presentación y anÁlisis de Resultados}

En correspondencia con la metodología empleada, a continuación se mencionan las ferias analizadas:

- La FILEM surge en 2007. Su sede es la ciudad de Toluca, Estado de México. La organiza el Gobierno del Estado de México, el Ayuntamiento y la Universidad Autónoma del Estado de México (UAEM).

- La Feria Internacional del Libro de Nezahualcóyotl surge en 2013. Su sede es Nezahualcóyotl, Estado de México. La organiza la Dirección de Educación y Fomento a la Cultura del Ayuntamiento, en coordinación con la Brigada para Leer en Libertad A. C.

- La Feria Internacional del Libro de Texcoco surge en 2013. Su sede es Texcoco, Estado de México. La organiza el Ayuntamiento por medio de la Dirección de Cultura y la Brigada Para Leer en Libertad A. C.

- La Feria del Libro de Chapingo tiene su sede en las instalaciones del Campus de la Universidad. La organiza la Universidad Autónoma de Chapingo.

- La Feria del Libro del Tecnológico de Estudios Superiores de Ecatepec (TESE) tiene su sede en Ecatepec, Estado de México. La organiza el TESE.

- La Feria del Libro y la Lectura de Tlalnepantla surge en 2019. Su sede es Tlalnepantla, Estado de México.

Pues bien, una vez determinadas las ferias se concentró la Tabla 1 con sus respectivas categorías de análisis. 


\begin{tabular}{|c|c|c|c|}
\hline Feria & Categoría: Espacio físico & $\begin{array}{c}\text { Categoría: } \\
\text { Comercialización }\end{array}$ & $\begin{array}{l}\text { Categoría: } \\
\text { Actividades }\end{array}$ \\
\hline FILEM & $\begin{array}{l}\text { La feria se realiza en luga- } \\
\text { res cerrados; sin embargo, } \\
\text { se ha ido descentralizando } \\
\text { con respecto de la primera } \\
\text { edición, para que un mayor } \\
\text { número de personas tenga } \\
\text { oportunidades de asistir. }\end{array}$ & $\begin{array}{l}\text { La entrada a la feria así como } \\
\text { a los eventos es gratuita. }\end{array}$ & $\begin{array}{l}\text { Hay cuentacuentos } \\
\text { que se encargan de } \\
\text { leer y actuar cuentos } \\
\text { para aquellos infantes } \\
\text { o personas mayores } \\
\text { analfabetas, o bien para } \\
\text { personas que sufren de } \\
\text { deficiencia visual. } \\
\text { Hay un Librobús que } \\
\text { circula por diferentes } \\
\text { espacios de la feria, a fin } \\
\text { de acercar los libros a los } \\
\text { asistentes. }\end{array}$ \\
\hline $\begin{array}{c}\text { Feria } \\
\text { Internacional } \\
\text { del Libro } \\
\text { de Nezahualcóyotl }\end{array}$ & $\begin{array}{l}\text { Se lleva a cabo en la } \\
\text { explanada municipal, la } \\
\text { cual es considerada la } \\
\text { más importante de la zona } \\
\text { metropolitana del Valle de } \\
\text { México. }\end{array}$ & $\begin{array}{l}\text { La entrada a la feria así como } \\
\text { a los eventos es gratuita. } \\
\text { Se han obsequiado libros. } \\
\text { Se han ofrecido ediciones a } \\
\text { precios accesibles para que } \\
\text { los lectores puedan adquirir } \\
\text { sus ejemplares. }\end{array}$ & $\begin{array}{l}\text { Hay participación de } \\
\text { policías municipales } \\
\text { de Nezahualcóyotl que } \\
\text { forman parte del progra- } \\
\text { ma Literatura Siempre } \\
\text { Alerta, que se desarrolla } \\
\text { desde hace varios años, } \\
\text { en donde además de } \\
\text { realizar sus tareas de } \\
\text { vigilancia las combinan } \\
\text { con la lectura en un es- } \\
\text { pacio que los une a ellos } \\
\text { como corporación. }\end{array}$ \\
\hline $\begin{array}{c}\text { Feria } \\
\text { Internacional } \\
\text { del Libro } \\
\text { de Texcoco }\end{array}$ & $\begin{array}{l}\text { Se realiza en diferentes } \\
\text { puntos del municipio, } \\
\text { incluyendo el propio } \\
\text { Jardín Municipal, a fin de } \\
\text { tener un espacio abierto } \\
\text { en donde se promueva la } \\
\text { participación de todos los } \\
\text { habitantes. Una actividad } \\
\text { que une a la comunidad es } \\
\text { el teatro al aire libre, que } \\
\text { brinda la posibilidad de } \\
\text { que cualquier persona se } \\
\text { sienta con mayor libertad } \\
\text { de presenciarlo. } \\
\text { Se realiza un desfile de } \\
\text { personas con vestuarios } \\
\text { típicos de la región por las } \\
\text { calles del lugar al ritmo de } \\
\text { tambores y trompetas para } \\
\text { hacer de la feria una fiesta. }\end{array}$ & $\begin{array}{l}\text { La entrada a la feria así como } \\
\text { a los eventos es gratuita. }\end{array}$ & $\begin{array}{l}\text { Se cuenta, especial- } \\
\text { mente, con un pabellón } \\
\text { infantil en el que los } \\
\text { niños disfrutan de } \\
\text { talleres, espectáculos de } \\
\text { cuentacuentos y otras } \\
\text { actividades en torno a la } \\
\text { lectura. } \\
\text { Hay un Librobús que } \\
\text { circula por diferentes } \\
\text { espacios de la feria, a fin } \\
\text { de acercar los libros a los } \\
\text { asistentes. }\end{array}$ \\
\hline
\end{tabular}




\begin{tabular}{|c|c|c|c|}
\hline $\begin{array}{l}\text { Feria del Libro } \\
\text { de Chapingo }\end{array}$ & $\begin{array}{l}\text { Además de la Feria, siem- } \\
\text { pre tiene lugar simultánea- } \\
\text { mente la tradicional Feria } \\
\text { Nacional de la Cultura } \\
\text { Rural con la finalidad de } \\
\text { que todos los visitantes } \\
\text { puedan disfrutar de un } \\
\text { mosaico multicultural. } \\
\text { De esta manera acuden } \\
\text { multitud de artesanos } \\
\text { provenientes de las dife- } \\
\text { rentes partes de México y } \\
\text { se propicia un espacio de } \\
\text { cultura tradicional. }\end{array}$ & $\begin{array}{l}\text { La entrada a la feria así como } \\
\text { a los eventos es gratuita. }\end{array}$ & $\begin{array}{l}\text { A pesar de ser una } \\
\text { institución líder en publi- } \\
\text { caciones especializadas } \\
\text { en el área agronómica, } \\
\text { esta feria dedica } \\
\text { distintas actividades } \\
\text { como presentaciones, } \\
\text { conferencias, lecturas, } \\
\text { exposiciones y talleres } \\
\text { infantiles a fin de reunir a } \\
\text { este tipo de comunidad. }\end{array}$ \\
\hline $\begin{array}{l}\text { Feria del Libro } \\
\text { del TESE }\end{array}$ & $\begin{array}{l}\text { La feria se realiza de } \\
\text { manera cerrada en las } \\
\text { instalaciones del TESE. }\end{array}$ & $\begin{array}{l}\text { Se han ofrecido ediciones a } \\
\text { precios accesibles para que } \\
\text { los lectores puedan adquirir } \\
\text { sus ejemplares. }\end{array}$ & $\begin{array}{l}\text { Hay cuentacuentos } \\
\text { que se encargan de } \\
\text { leer y actuar cuentos } \\
\text { para aquellos infantes } \\
\text { o personas mayores } \\
\text { analfabetas, o bien para } \\
\text { personas que sufren de } \\
\text { deficiencia visual. }\end{array}$ \\
\hline $\begin{array}{l}\text { Feria del Libro } \\
\text { y la Lectura } \\
\text { de Tlalnepantla }\end{array}$ & $\begin{array}{l}\text { Se lleva a cabo en la plaza } \\
\text { cívica de Tlalnepantla } \\
\text { centro. }\end{array}$ & $\begin{array}{l}\text { La entrada a la feria así como } \\
\text { a los eventos es gratuita. } \\
\text { Durante las presentaciones } \\
\text { del libro y mesas de diálogo se } \\
\text { obsequian ejemplares a fin de } \\
\text { difundir la lectura para todos. } \\
\text { Hay oferta de libros. }\end{array}$ & $\begin{array}{l}\text { Se realizan lecturas en } \\
\text { voz alta a partir de los } \\
\text { propios escritores invi- } \\
\text { tados a fin de que exista } \\
\text { unión entre todos los } \\
\text { asistentes, sin distinción } \\
\text { alguna. } \\
\text { Hay un Librobús que } \\
\text { circula por diferentes } \\
\text { espacios de la feria, a fin } \\
\text { de acercar los libros a los } \\
\text { asistentes. }\end{array}$ \\
\hline
\end{tabular}

Tabla 1. Categorías de análisis observadas en las ferias del libro del Estado de México Fuente: elaboración propia

Una vez que se han presentado las seis ferias del libro del Estado de México, así como las categorías de análisis observadas en cada una de ellas, conviene comentar también la inesperada situación de la pandemia por COVID-19, que obligó a las ferias del libro a modificar su accionar o incluso a suspenderse ya que este tipo de exposiciones poseen la característica de ser eventos con grandes masas en donde se desarrolla la compra-venta de material de lectura.

Ante esta situación se tuvo la posibilidad de continuar realizando compras de material de lectura a través de las tarjetas de crédito, desde esa perspectiva el mercado siguió funcionando. Sin embargo, esto cobró factura con una brecha difícil de cerrar porque para seguir con los cuidados durante la 
contingencia sanitaria la mayor parte de los eventos se transmitieron por medios tecnológicos, en algunos casos sólo de manera presencial hubo exposición de libros por parte de editoriales y actividades con un aforo limitado, razón por la que es posible afirmar que se priorizó la venta de material sobre cualquier actividad de fomento a la lectura e inclusión social.

De esta manera se cerró la posibilidad de que hubiera acceso para la sociedad menos favorecida. Al realizar las ferias de manera virtual el espacio dejó de ser físico, cambió de su modalidad gratuita al acceso de unos cuantos, pasó a ser sólo de los que disponían de las tecnologías para ser partícipes del evento; también las actividades se vieron modificadas y no hubo necesidad de planearlas en relación a cierta comunidad, mucho menos a comunidades desfavorecidas. La dinámica cambió radicalmente, al ser un evento virtual su difusión también lo fue; en ese sentido se olvidó que a pesar de los grandes avances tecnológicos es necesario difundir desde los medios tradicionales como radio, televisión y periódico, a fin de que el comunicado llegue a más personas, sobre todo si se quiere trabajar en favor de la inclusión social.

Fue un desafío que las ferias del libro tuvieran que ingeniar un plan que les permitiera seguir en circulación, desafortunadamente siguió existiendo prioridad por la parte económica.

\section{Discusión}

A partir de esta investigación realizada en el Estado de México se han podido establecer interpretaciones y comparaciones con respecto a lo que ocurre en otras latitudes.

Es de observarse que, por ejemplo, un referente de feria en México es la Feria Internacional del Libro de Guadalajara (FIL), la cual se ha destacado por ser un escenario que apuesta por llevar la lectura a todos sus visitantes. Algunas acciones que la FIL ha emprendido son poner al alcance de los usuarios ediciones en braille o bien trabajar con la enseñanza de la Lengua de Señas Mexicana (LSM). Además, la FIL ha organizado el Encuentro de Promotores de Lectura en donde se ha abordado el tema de la "lectura inclusiva", a fin de trabajar en beneficio de personas con necesidades especiales, personas pertenecientes a minorías étnicas desfavorecidas, poblaciones migrantes, comunidades remotas y aisladas o barrios urbanos marginales.

Aquí es meritorio mencionar que Guadalajara tiene el reconocimiento a nivel internacional al ser nombrada la capital mundial del libro 2022, esa mención se dio gracias al trabajo en conjunto de varias dependencias y, por 
supuesto, a la FIL de Guadalajara. Este es un claro ejemplo de que la lectura debe tener mayor proyección, valerse como medio para la inclusión y no solamente visualizarse en una feria del libro desde una vitrina para la industria editorial. En el caso de Guadalajara el programa propuesto que se está trabajando y por el cual se le otorgó el nombramiento se centra en tres ejes estratégicos: la recuperación de los espacios públicos mediante actividades de lectura en parques y otros espacios accesibles; vinculación y cohesión social, especialmente a través de talleres de lectura y escritura para niños, y el fortalecimiento de la identidad de barrio mediante las conexiones intergeneracionales, la narración de cuentos y la poesía callejera.

Sin duda, los avances que ha hecho la FIL en materia de inclusión durante los últimos años son de reconocerse, pues el trabajo en esa materia es constante ya que actualmente se ha logrado la incorporación de intérpretes de LSM en eventos y foros de la feria, así como el cuidado en las cuestiones de movilidad dentro de las instalaciones para personas con silla de ruedas.

Ahora bien, aquí es evidente que a pesar de la comercialización que se desarrolla en la Feria del Libro de Guadalajara existe un plan para que la lectura sirva como estrategia de inclusión social. Caso contrario, en las ferias analizadas del Estado de México no se logró obtener algún documento que diera evidencia de que se está trabajando desde la lectura como un medio táctico para trabajar en beneficio de la inclusión social, pues la estrategia discursiva que se percibe es en relación con el número de expositores, la presencia masiva de editores y libreros, la exhibición de títulos, las actividades culturales y académicas, así como los récords en el número de visitantes y el movimiento financiero.

Con esto es posible diferenciar que en las ferias del libro del Estado de México aún hay pendientes por desarrollar con relación al tema de inclusión social a partir de la lectura, ya que a través de estas comparaciones se visualiza claramente que hace falta poner el tema de la lectura en la parte central y observar el impacto que ésta tiene en la cohesión social. Así lo asevera Restrepo Fernández (2020: 108) cuando dice que "la alfabetización y la lectura propician procesos de interacción social más justos e igualitarios entre la población, equiparando diferencias educativas, culturales y sociales mediante la alfabetización y el fomento de la lectura".

Teniendo en cuenta el poder de la lectura como estrategia de inclusión social y considerando que algunas de las ferias analizadas tienen alrededor de 10 años llevándose a cabo, entonces debería haber mayores avances desde un discurso planeado y enfocado en relación a esta dinámica, que, por supuesto, se traduzca en acciones. 


\section{Conclusiones}

Como parte de las recomendaciones para lograr la inclusión social desde la lectura y a fin de no perder la génesis de las ferias de libro, la cual tiene que ver con la cuestión económica, es importante que estas actividades culturales tengan un plan definido para incluir a la sociedad en general. "La feria convoca a la socialización, al encuentro con otros similares" (Pérez Camacho y López Ojeda, 2015: 51), y así se afirma que "la feria del libro implica hablar de fiesta del libro si se hace honor a la etimología. Y, en esa fiesta, los convidados tienen que ser todos" (Uribe Schroeder y Zapata López, 2012: 43).

De ahí que sea necesario planificar las estrategias adecuadas para ir rompiendo paulatinamente las barreras que impiden la inclusión social a las ferias del libro, quitando los prejuicios de que éstas son sólo para unos cuantos. Derivado de la presente investigación se sugiere tomar en cuenta las siguientes observaciones para que, en un momento dado, ayuden en la organización de las ferias del libro y aporten con mira a las estrategias de inclusión social:

- En cuanto a la categoría Espacio físico, se minimiza la barrera física y se permite la inclusión social al instalar las ferias en lugares abiertos como las plazas públicas, ya que de esta manera se abre la posibilidad de incidir, entre otras cosas, en la promoción de la lectura y en la construcción de nuevos lectores, sobre todo de aquellos que generalmente tienen poco acercamiento. Sólo debe cuidarse que el lugar cuente con las condiciones necesarias para recibir al mayor número de personas posible, considerando el uso de rampas (aunque sea provisionales), pasamanos, asientos y buena iluminación. Además, el hecho de proporcionar transporte gratuito desde determinadas zonas estratégicas hacia el lugar donde se encuentra la feria del libro brinda oportunidades para que las personas se acerquen a ésta.

- En cuanto a la categoría Comercialización, se disminuye la barrera económica permitiendo la inclusión social a partir de descuentos o precios especiales que atraigan a los ciudadanos al consumo cultural y la promoción de la lectura. "Esto se reafirma con la percepción de que en estos eventos se pueden encontrar libros a bajo precio, de manera que un mensaje indirecto es que la lectura está al alcance de todos" (Pérez Camacho y López Ojeda, 2015: 50-51). Además, ofrecer la entrada gratis determinados días o a determinados sectores de la población contribuye al acceso de personas con pocas posibilidades.

- En cuanto a la categoría Actividades, se reducen las barreras intelectuales e informativas permitiendo la inclusión social a partir de acciones como 
ruedas de lecturas compartidas, cuentacuentos, lecturas en voz alta y juegos lúdico-pedagógicos. De esta manera, si bien el objetivo primordial de las ferias tiene que ver con la comercialización, se ofrece contacto con los materiales de lectura a través de una reunión, tertulia o círculo con los asistentes.

Por último, es importante señalar que el paso hacia la inclusión no es inmediato, sino que es gradual y exige un compromiso a largo plazo. Pero, definitivamente, es un buen inicio discutir sobre el tema en cuanto al reconocimiento a los grupos excluidos e "invisibles" para dar marcha a soluciones a través de estrategias o incluso de políticas culturales que acrediten un respaldo en este asunto, sin duda, de interés social.

Aquí la importancia de estas investigaciones que buscan, entre otras cosas, analizar y proponer a fin de propiciar, con las bases necesarias, nuevos campos jurídicos, normativos y culturales, ya que es preciso construir condiciones prometedoras para la inclusión social a través de prácticas culturales como lo es la lectura, y para ello se requiere promover una política incluyente y no sólo una política sexenal que tenga la capacidad de permanecer más allá de las temporalidades administrativas o de partidos políticos.

Agradecimientos

La presente investigación es el resultado de un proyecto de estancia posdoctoral financiada por CONACYT y respaldada por El Colegio Mexiquense A. C., que se inserta dentro del programa Conacyt-Pronaces.

\section{REFERENCIAS}

Ceretta Soria, María Gladys. 2012. "Políticas y planes de lectura: el caso de Uruguay”. Palabra clave (La Plata) 2 (1): 35-50.

https://www.redalyc.org/articulo.oa?id=350539935004

Deberti Martins, Cristina. 2011. "La lectura: una herramienta de inclusión social". Boletin ANABAD 2 (3): 103-112.

https://dialnet.unirioja.es/servlet/articulo? codigo $=4104364$

De Souza Siqueira, Thiago Giordano. 2016. "Lectura, biblioteca e inclusión social: importancia de la promoción de la lectura en comunidades ribereñas en Amazonas, Brasil”. Información, Cultura y Sociedad (34): 93-105.

http://revistascientificas.filo.uba.ar/index.php/ICS/article/view/2256

López Villalobos, Dayana. 2014. “¿Ferias o mercados? Representaciones sobre el libro, la lectura y la escritura en el marco de las ferias del libro”. Quórum académico 1 (11): 112-134. 
Pastor Homs, Ma. Inmaculada. 2004. Pedagogía museística. Nuevas perspectivas y tendencias actuales. España: Ariel Patrimonio.

Pérez Camacho, Carmen y Andrés López Ojeda. 2015. "Los usos sociales de la lectura: del modo tradicional a otras formas colectivas de leer". Hacia una antropología de los lectores, coordinado por Néstor García Canclini, 39-104. México: UAM Iztapalapa.

Ramírez Alvarado, María Matilde. 2015. "La feria del libro y sus funciones". Boletín de la Asociación Andaluza de Bibliotecarios 30: 47-53.

https://dialnet.unirioja.es/servlet/articulo? codigo $=5468159$

Ramírez Alvarado, María Matilde. 2016. "Análisis de las funciones de la feria del libro en América Latina: girar alrededor del libro y su mundo”. Revista Educación $y$ Valores (2): 17-25.

https://dialnet.unirioja.es/servlet/articulo? codigo $=7021610$

Restrepo Fernández, María Camila. 2020. "Alfabetización y lectura: prácticas socioculturales para la inclusión social desde la biblioteca pública”. Tesis de maestría, Universidad Nacional Autónoma de México, Instituto de Investigaciones Bibliotecológicas y de la Información.

Uribe Schroeder, Richard y Fernando Zapata López. 2012. Las ferias del libro. Manual para expositores y visitantes profesionales. Colombia: CERLALC-UNESCO.

Para citar este texto:

Vivero Domínguez, Carmina. 2022. "La lectura como estrategia de inclusión social en las ferias del libro del Estado de México”. Investigación Bibliotecológica: archivonomía, bibliotecología e información 36 (90): 165-177.

http://dx.doi.org/10.22201/iibi.24488321xe.2022.90.58516 